\title{
QUALIDADE DOS TOMATES DE MESA COMERCIALIZADOS EM JATAÍ - GO
}

\section{Yuri Fernando Lino Ferreira ${ }^{1}$ \\ Letícia Martins de Sousa² \\ José Hortêncio Mota ${ }^{3}$}

Resumo: Este estudo teve por objetivo realizar um levantamento da qualidade dos tomates de mesa comercializados no município de Jataí - GO. A amostragem foi realizada de forma aleatória em sete estabelecimentos comerciais. Para a avaliação da qualidade, as variáveis analisadas foram peso, diâmetro, comprimento e espessura da parede de cada fruto. Sendo também realizadas classificações quanto ao formato, coloração e quantidade de defeitos além da determinação do teor dos sólidos solúveis (brix). Os resultados obtidos foram avaliados por meio de estatística descritiva. Verificou-se que os frutos de tomate comercializados em Jataí apresentaram padrão similar em todos os estabelecimentos amostrados, sendo caracterizados por apresentarem coloração salada com tamanho pequeno e com ausência de defeitos ou injúrias.

Palavras-chave: Lycopersicon esculentum Mill, classificação de hortaliças, pós-colheita.

\footnotetext{
1Universidade Federal de Goiás - Regional Jataí, Cx Postal 3, 75801-615, Jataí - GO, adriellyagseverino@gmail.com. Goiás _ Regional Jataí, Cx Postal 3, 75801-615 Jataí - Go, Universidade Federal de leticia.martins.agro@gmail.com ${ }^{3}$ Universidade Federal de Goiás - Regional Jataí, Cx Postal 3, 75801-615, Jataí - Go, hortenciomota@ufg.br.
} 